ヤーコン地上部の抗酸化活性と $\alpha$-グルコシダーゼ阻害活性に関する成分

寺田澄男, ${ }^{*}$ 伊藤紀久夫, 吉村 朗, 野口直人, 石田 崇

\title{
The Constituents Relate to Anti-oxidative and $\alpha$-Glucosidase Inhibitory Activities in Yacon Aerial Part Extract
}

\author{
Sumio Terada, ${ }^{*}$ Kikuo Ito, Akira Yoshimura, \\ Naoto NoGUCHI, and Takashi ISHIDA \\ Research Laboratory, Zenyaku Kogyo Co. Ltd., 2-33-7, Ohizumi-machi, \\ Nerima-ku, Tokyo 178-0062, Japan
}

(Received March 2, 2006; Accepted May 15, 2006)

\begin{abstract}
Hot water extract of the aerial part of Yacon (Smallanthus sonchifolia, Compositae) showed potent free radicalscavenging activity and inhibitory effects on lipid peroxidation in rat brain homogenate. The most potent antioxidative activity focused on the $50 \% \mathrm{MeOH}$-eluted fraction on DIAION HP-20 column chromatography. The structure of the major component in the fraction was identified as 2,3,5-tricaffeoylaltraric acid (TCAA) based on spectroscopic evidence. The antioxidative activity of TCAA is superior to that of natural antioxidants such as $( \pm)$-catechin, $\alpha$ tocopherol, and ellagic acid, and TCAA also showed selective maltase-inhibitory activity $\left(\mathrm{IC}_{50} 49 \mu \mathrm{g} / \mathrm{ml}\right)$. As the hypoglycemic activity of Yacon extract was described in a previous report, the present results showing that the aerial part of Yacon has strong antioxidative activity may encourage its potential use as a food supplement to prevent type II diabetes.
\end{abstract}

Key words — Smallanthus sonchifolia; antioxidant; tricaffeoylaltraric acid; $\alpha$-glucosidase inhibitory activity; Yacon

緒 言

ヤーコン（Smallanthus sonchifolia）はアンデス 山地原産のキク科植物である。われわれは，ヤーコ ン地上部熱水エキスに血糖上昇抑制活性を見出し, 作用発現に $\alpha$-グルコシダーゼ阻害活性が関与して いること，またエキス中の 3,4- ジカフェオイルキ ナ酸などのジカフェオイルキナ酸（DCQA）類が 強力かつ選択的な $\alpha-$ グルコシダーゼ阻害活性を有 することを報告している. ${ }^{11}$

最近, 活性酸素が膵臓ランゲルハンス氏島に作用 して糖尿病発症を促進し，これが抗酸化物質投与に より抑制されることが報告2,3)されている。 また, 抗酸化活性を有するポリフェノールにより, STZ 誘発糖尿病マウスの血糖值が低下することも報告さ れている. ${ }^{4)}$ Caffeic acid や DCQA 類には抗酸化活 性のあることが知られている5,6)ことから, ヤーコ ン地上部エキスについて検討したところ， $\alpha$ -

全薬工業株式会社中央研究所

*e-mail: Sumio_Terada@mail.zenyaku.co.jp tocopherol や $( \pm)$-catechin に匹敵する強力な抗酸 化活性が見出された。活性成分の探索の結果，抗酸 化活性は前記の $\alpha$ - グルコシダーゼ阻害活性と同様 に，熱水エキスの DIAION HP-20 カラムクロマト グラフィーの $50 \% \mathrm{MeOH}$ 溶出画分に収斂した. HPLC 分析により，本画分は caffeoyl 基を有するポ リフェノール成分の混合物であることが判り, DCQA などの $\alpha$-グルコシダーゼ阻害活性成分が検 出された. 同時に, これまで未検出で含量の高い成 分が認められたことから精製を行い, 既知物質 2,3,5-tricaffeoylaltraric acid（TCAA）を分離した。 本化合物を他の天然物由来の抗酸化活性成分とと もに評価し，並びに $\alpha$-グルコシダーゼ阻害活性に ついて検討したので報告する.

\section{実 験 の 部}

NMR は JNM-EX400（日本電子）にて測定し， 内部標準は TMS を用いた。なお, doubletは d, double doublet は dd と各々略した。高分解能 FAB-MS は，JMS-SX102A（日本電子）にて測定 
した。UV スペクトルは UV-2550（島津製作所）， 比旋光度は SEPA-300（堀場製作所）により各々測 定した. HPLC はポンプ LC-10Atvp, UV/フォトダ イオードアレー検出器 SPD-M10Avp, カラムオー ブン CTO-10Asvp, システムコントローラーSCL10Avp（いずれも島津製作所）を用いて行った.

カラムクロマトグラフィー用の担体は，DIAION HP-20（日本鍊水）, LiChroprep RP-18（メルク）, TOYOPEARL HW-40F (東ソー), Sephadex LH-20 （アマシャム）を用いた.

1. ヤーコンの栽培 ヤーコンは 2002 年東京 都練馬区大泉町 2 丁目の全薬工業侏中央研究所戋場 にて, 茨城大学農学部月橋輝男教授より恵与頂いた ペルーA 系ヤーコンの種芋を用いて栽培した。

2. 脳ホモジネート自動酸化試験 Ohkawa ら の方法7)に準じて，チオバルビツール酸法により測 定した。

3. 1,1-Diphenyl-2-picrylhydrazyl (DPPH) ラジ カル捕捉試験 Blois らの方法 ${ }^{8}$ に準じて測定し た.

\section{4. 糖水解酵素阻害活性試験 $\quad \alpha$-アミラーゼ,} マルターゼ，及びスクラーゼ阻害活性はいずれも前 報1 に記載の方法により測定した。

5. TCAA の分離 ヤーコン地上部 $100 \mathrm{~g}$ を 1 1 の $70^{\circ} \mathrm{C}$ 熱水で 15 分間攪汼抽出し, 熱時綿栓濾過 した。濾液を濃縮・凍結乾燥し, 暗褐色粉末 $17.3 \mathrm{~g}$ を得た。この全量を DIAION HP-20 カラムクロマ トグラフィー $(30 \mathrm{~mm} \phi \times 200 \mathrm{~mm})$ に付し，水，50 $\% \mathrm{MeOH} /$ 水, $\mathrm{MeOH}$ 各 11 で順次溶出後, 濃縮し て凍結乾燥し, 水溶出部 $13.9 \mathrm{~g}, 50 \% \mathrm{MeOH} /$ 水溶 出部 $2.21 \mathrm{~g}, \mathrm{MeOH}$ 溶出部 $0.48 \mathrm{~g}$ を各々得た。 $50 \%$ $\mathrm{MeOH} /$ 水溶出部 $2.19 \mathrm{~g}$ を 2 回に分けて LiChroprep RP-18 カラムクロマトグラフィー $(35 \mathrm{~mm} \phi \times 370$ $\mathrm{mm}$ ）に付し， MeOH-5\%酢酸（3:7)，ついで $\mathrm{MeOH}-5 \%$ 酢酸 (4:6) で溶出した. $\mathrm{MeOH}-5 \%$ 酢 酸 $(4: 6)$ 溶出部を維め, TOYOPEARL HW-40F カラムクロマトグラフィー $(\mathrm{MeOH}-$ 水 $=3: 7 \rightarrow 9:$

1), Sephadex LH-20 カラムクロマトグラフィー $(\mathrm{MeOH}-$ 水 $=8: 2)$ にて分離し, 淡黄色粉末とし て TCAA を $11.6 \mathrm{mg}$ を得た。

6. TCAA 淡黄色粉末, $[\alpha]_{\mathrm{D}}+31^{\circ} \quad(\mathrm{c}=0.2$, $\mathrm{MeOH}$ ), High Resolution FAB-MS (negative) $\mathrm{m} / \mathrm{z}$ : $695.1200\left(\mathrm{M}^{+}-\mathrm{H}\right)$ for $\mathrm{C}_{33} \mathrm{H}_{28} \mathrm{O}_{17}$, UV $\lambda \max (\mathrm{EtOH})$ $\mathrm{nm}(\log \varepsilon): 244(4.28), 328(4.50),{ }^{1} \mathrm{H}-\mathrm{NMR}\left(\mathrm{CD}_{3}\right.$ OD) $\delta: 4.84(1 \mathrm{H}, \mathrm{dd}, J=9.0,2.0 \mathrm{~Hz}), 5.28(1 \mathrm{H}, \mathrm{d}, J$ $=2.0 \mathrm{~Hz}), 5.65(1 \mathrm{H}, \mathrm{dd}, J=9.0,2.0 \mathrm{~Hz}), 5.66(1 \mathrm{H}$, d, $J=2.0 \mathrm{~Hz}), 6.22(1 \mathrm{H}, \mathrm{d}, J=15.9 \mathrm{~Hz}), 6.366(1 \mathrm{H}$, d, $J=15.9 \mathrm{~Hz}), 6.371(1 \mathrm{H}, \mathrm{d}, J=15.9 \mathrm{~Hz}), 6.74$ $(1 \mathrm{H}, \mathrm{d}, J=8.3 \mathrm{~Hz}), 6.77(1 \mathrm{H}, \mathrm{d}, J=8.0 \mathrm{~Hz}), 6.78$ $(1 \mathrm{H}, \mathrm{d}, J=8.3 \mathrm{~Hz}), 6.91(1 \mathrm{H}, \mathrm{dd}, J=8.3,1.9 \mathrm{~Hz})$, $6.970(1 \mathrm{H}, \mathrm{dd}, J=8.3,1.8 \mathrm{~Hz}), 6.974(1 \mathrm{H}, \mathrm{dd}, J=$ $8.3,1.8 \mathrm{~Hz}), 7.02(1 \mathrm{H}, \mathrm{d}, J=1.9 \mathrm{~Hz}), 7.08(1 \mathrm{H}, \mathrm{d}, J$ $=1.9 \mathrm{~Hz}), 7.09(1 \mathrm{H}, \mathrm{d}, J=1.9 \mathrm{~Hz}), 7.53(1 \mathrm{H}, \mathrm{d}, J=$ $15.9 \mathrm{~Hz}), 7.64(1 \mathrm{H}, \mathrm{d}, J=15.8 \mathrm{~Hz}), 7.66(1 \mathrm{H}, \mathrm{d}, J=$ $16.1 \mathrm{~Hz}),{ }^{13} \mathrm{C}-\mathrm{NMR}\left(\mathrm{CD}_{3} \mathrm{OD}\right) \delta: 69.9,72.7(2 \mathrm{C})$, $73.1,113.9,114.1,114.2,115.3$ (3C), 116.5 (3C), 123.4 (2C) , 123.5, 127.6, 127.7, 127.8, 146.8 (2C), $146.9,148.2,148.40,148.43,149.8,149.9$ (2C), 167.4, 168.1, 168.4, 170.4, 171.6.

\section{7. ヤーコン地上部エキス中の TCAA の定量}

カラム : YMC ODS-A 120 -S5 $\quad(4.6 \mathrm{~mm} \phi \times 150$ $\mathrm{mm})$, 移動相 : $0.1 \%$ リン酸 $/ \mathrm{THF}$ 混液 $(7: 3)$, 力 ラム温度 : $40^{\circ} \mathrm{C}$, 流量 : $1.0 \mathrm{ml} / \mathrm{min}$., 検出波長 : $332 \mathrm{~nm}$.

エキス約 $0.1 \mathrm{~g}$ を精密に量り，移動相に溶解し正 確に $50 \mathrm{ml}$ とし試料溶液とした。別途，上記方法で 分離・精製した TCAA 標準品約 $0.01 \mathrm{~g}$ を精密に量 り，THF に溶解し正確に $50 \mathrm{ml}$ とした。この液 2 $\mathrm{ml}$ に $0.1 \%$ リ酸 $15 \mathrm{ml}$ を加え混和した後, 移動相 を加えて正確に $50 \mathrm{ml}$ とし標準溶液とした。試料溶 液及び標準溶液を孔径 $0.45 \mu \mathrm{m}$ のメンブランフィル ターで濾過し， $20 \mu \mathrm{l}$ ずつを HPLCに注入し，各液 の TCAA のピーク面積 $\mathrm{A}_{\mathrm{T}}$ 及び $\mathrm{A}_{\mathrm{S}}$ を測定し，以下 の式によりエキス $1 \mathrm{~g}$ 中の TCAA 量を算出した.

エキス $1 \mathrm{~g}$ 中の $\mathrm{TCAA}$ 量 $(\mathrm{mg})$

$=$ 標準品採取量 $(\mathrm{mg}) \times \mathrm{f} \times(1 / 25) \times\left(\mathrm{A}_{\mathrm{T}} / \mathrm{A}_{\mathrm{S}}\right)$ $\times(1 \mathrm{~g} /$ エキス採取量 $\mathrm{g})$

$\mathrm{f}:$ 標準品純度 $(\%) / 100$

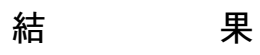

ヤーコン地上部エキスを DIAION HP-20 カラム クロマトグラフィーに付して得られた水，50\% $\mathrm{MeOH} /$ 水, $\mathrm{MeOH}$ 各溶出画分の抗酸化活性を調へ たところ，Table 1 に示すように $50 \% \mathrm{MeOH}$ 溶出 部に活性は収斂した。この画分をUV/フォトダイ オードアレー検出器を接続した HPLC で多波長分 
Table 1. Antioxidant Activities of Fractions and Phenols from Yacon Extract

\begin{tabular}{lcc}
\hline \hline \multicolumn{1}{c}{ Sample } & $\begin{array}{c}\text { Inhibitory activities } \\
\text { on lipid peroxidation }\end{array}$ & $\begin{array}{c}\text { DPPH radical } \\
\text { scavenging activities }\end{array}$ \\
\cline { 2 - 3 } & $\mathrm{IC}_{50}: \mu \mathrm{g} / \mathrm{ml}$ & $\mathrm{EC}_{50}: \mu \mathrm{g} / \mathrm{ml}$ \\
\hline Yacon hot water extract & 6.65 & 15.38 \\
HP20-water & 20.96 & 32.19 \\
HP20-50\% MeOH & 1.9 & 2.78 \\
HP20-MeOH & 24.24 & 13.12 \\
3,4-DCQA & $1.48(2.87)$ & $0.91(1.76)$ \\
3,5-DCQA & $2.18(4.23)$ & $0.87(1.69)$ \\
4,5-DCQA & $3.38(6.55)$ & $0.89(1.72)$ \\
TCAA & $0.49(0.70)$ & $0.69(0.99)$ \\
Isoquercitrin & $6.64(14.31)$ & $1.53(3.30)$ \\
Chlorogenic acid & $13.21(37.32)$ & $1.13(3.19)$ \\
( \pm -Catechin & $13.69(47.16)$ & $1.56(5.37)$ \\
$\alpha$-Tocopherol & $71.24(165.67)$ & $5.65(13.14)$ \\
Caffeic acid & $9.97(55.34)$ & $4.39(24.32)$ \\
Enzogenol & 2.17 & 1.94 \\
Ellagic acid & $0.56(1.85)$ & $0.51(1.69)$
\end{tabular}

( ) $: \mu_{\mathrm{M}}$

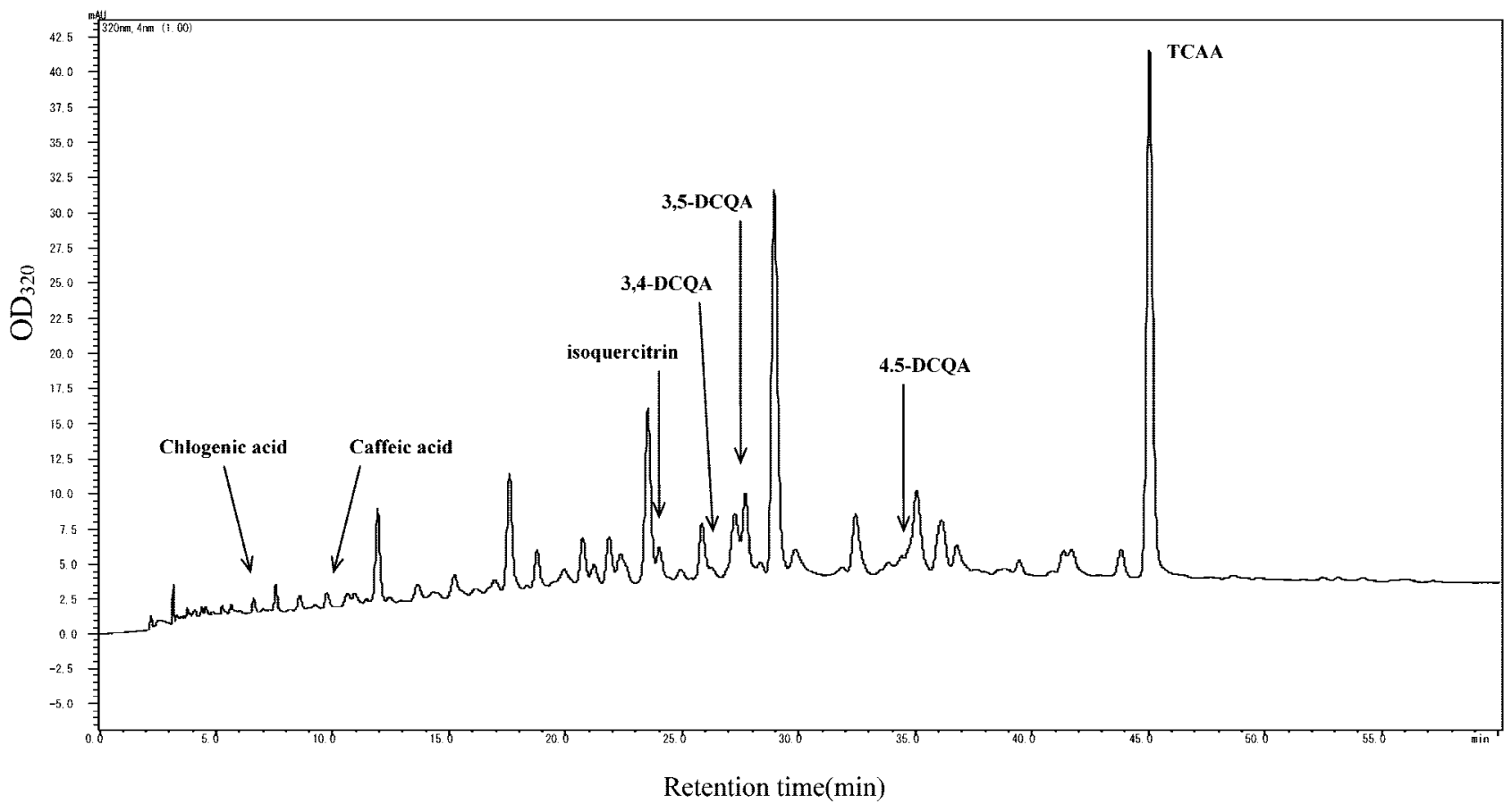

Fig. 1. HPLC Chromatogram of DIAION HP-20 50\% MeOH Fraction from Yacon Extract

HPLC conditions; Column: YMC-Pack R-ODS-5-A $(4.6 \mathrm{~mm} \phi \times 250 \mathrm{~mm})$, Mobile phase: A=acetonitrile, $\mathrm{B}=5 \%$ acetic acid in water, Gradient: $10-25 \% \mathrm{~A}$ in 60 minutes, Flow rate: $1.0 \mathrm{ml} / \mathrm{min}$., Detector: UV/photodiode array (at $320 \mathrm{~nm}$ ).

析したところ， $290 \mathrm{~nm}$ 及び $330 \mathrm{~nm}$ 付近に極大吸 収を有する成分が多数存在し，50\% $\mathrm{MeOH}$ 溶出部 は caffeoyl 基を有する成分からなると推定された. この画分には，3,4-DCQA，3,5-DCQA，4,5-DCQA， isoquercitrin など前報1) で報告した $\alpha$-グルコシダー
ゼ阻害活性成分が確認されたほか，これまで未確認 の高含量成分が検出された（Fig. 1）ことからカラ ムクロマトグラフィーにて分離・精製し， ${ }^{1} \mathrm{H}$ 及び ${ }^{13} \mathrm{C}-\mathrm{NMR}$ データの文献值 ${ }^{12)}$ との比較から，ヤーコ ン塊根部から抗酸化活性物質としての分離の報告 ${ }^{13)}$ 


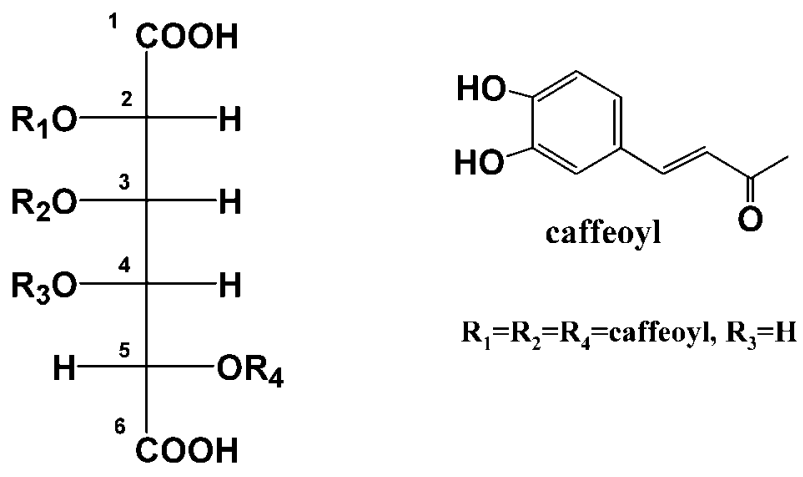

Fig. 2. Structure of TCAA

がある TCAA（Fig. 2） と同定した.

単離した TCAA と DCQA 類の抗酸化活性を, 天然物由来の抗酸化活性成分とともに過酸化脂質生 成抑制及び DPPH ラジカル捕捉試験により評価し た。 その結果，過酸化脂質生成抑制作用は，TCAA が最も強くモル濃度比較で $( \pm)$-catechin の 68 倍, ellagic acidの 2.5 倍の活性を示した。また, TCAA, DCQA 類の DPPH ラジカル捕捉作用は, chlorogenic acid, ${ }^{9)}$ ellagic acid, ${ }^{10)}$ enzogenol ${ }^{11)}$ と同 等で, $\alpha$-tocopherol よりは強いものであった（Table 1).

一方， $\alpha$-グルコシダーゼ阻害活性では， スク ラーゼ及びアミラーゼに対する阻害活性は弱かった が (それぞれ $\left.\mathrm{IC}_{50}>1000 \mu \mathrm{g} / \mathrm{ml}, \mathrm{IC}_{50}=420 \mu \mathrm{g} / \mathrm{ml}\right)$ ，

マルターゼに対しては強い阻害活性を示し（ $\mathrm{IC}_{50}=$ $49 \mu \mathrm{g} / \mathrm{ml})$, 対照とした acarbose に比べ 19 分の 1 の活性であった。

ヤーコン地上部エキス中の TCAA を定量した結 果, 含量は $0.25 \%$ であり, ヤーコン地上部エキス の $\alpha$ - グルコシダーゼ阻害活性 $\left(\mathrm{IC}_{50}=5.8 \mathrm{mg} / \mathrm{ml}\right)$ に対する寄与率は $30 \%$ と算出された.

\section{考察}

今回ヤーコン地上部より分離した強力な抗酸化活 性と $\alpha$-グルコシダーゼ阻害活性を有する TCAA は，同じヤーコンの塊根部より既に単離・報告 ${ }^{12)}$ れているものであるが， $\alpha$-グルコシダーゼ阻害活 性が認められたのは今回が最初である.

前報1)でわれわれは，ヤーコンの $\alpha$-グルコシ ダーゼ阻害活性成分は主として DCQA 類に拠ると していたが, 今回, 強い活性を有し, エキス中含量 の高い TCAAが得られた。TCAAの Sephadex
LH-20 カラムクロマトグラフィーにおいて，塩に なったものは $\mathrm{MeOH}$ 濃度の低いところで溶出さ れ，遊離のものは吸着されて溶出が遅くなり，前報 では TCAA の明確な阻害活性のピークが検出され なかったものと推定される.

DCQA 類は春菊, 5) ヨモギ14)など多くのキク科植 物やコーヒー豆 ${ }^{15)}$ に含まれていることが知られてお り，ヤーコン特有の $\alpha$-グルコシダーゼ阻害活性成 分とは言えないが，TCAA はこれまでにヤーコン 以外の植物より分離された報告はなく，エキス中に 占める含量も高いことからヤーコンエキスの $\alpha-ク ゙$ ルコシダーゼ阻害活性に関与する主成分と考えられ る.

また，TCAA は（土）-catechin よりも強い過酸化 脂質生成抑制効果を示し， $\alpha$-tocopherol と同等のラ ジカル捕捉効果を示した.

食後高血糖状態の繰り返しは膵 $\beta$ 細胞を傷害 し, 膵 $\beta$ 細胞容積の低下を伴うインスリン分泌の 障害を導き，II 型糖尿病の耐糖能をさらに悪化さ せ，空腹時高血糖を示すような糖尿病へと移行する と言われている. ${ }^{2,3)}$ また, 膵臓 $\beta$ 細胞の疲弊を抗酸 化物質が抑制することは多くの報告 ${ }^{16-18)}$ があり, 体内動態検討は今後の課題であるが，TCAAにも 同様の効果が期待される.

以上のように, ヤーコン地上部は抗酸化活性とマ ルターゼ選択的な $\alpha$-グルコシダーゼ阻害活性を併 せ持つ成分を多量に含んでおり，糖尿病発症予防に 有用な素材と考えられる。

\section{REFERENCES}

1) Terada S., Ito K., Taka M., Ogose N., Noguchi N., Koide Y., Nat. Med., 57, 89-94 (2003).

2) Tanaka Y., Gleason C. E., Tran P. O. T., Harmon J. S., Robertson R. P., Proc. Natl. Acad. Sci. U.S.A., 96, 10857-10862 (1999).

3) Katoh M., Sakurai K., Fujimoto Y., Yakugaku Zasshi, 122, 831-839 (2002).

4) Moharram F. A., Marzouk M. S., EI-Toumy S. A., Ahmed A. A., Aboutabl E. A., Phytother. Res., 17, 767-773 (2003).

5) Chuda Y., Ono H., Ohnishi-Kameyama M., Nagata T., Tsushida T., J. Agric. Food Chem., 44, 2037-2039 (1996). 
6) Ohnishi M., Morishita H., Toda S., Yase Y., Kido R., Phytochemistry, 47, 1215-1218 (1998).

7) Ohkawa H., Ohnishi N., Yagi K., Anal. Biochem., 95, 351-358 (1979).

8) Blois M. S., Nature, 181, 1199-1200 (1958).

9) Kweon M. H., Hwang H. J., Sung H. C., J. Agric. Food Chem., 49, 4646-4655 (2001).

10) Solon S., Lopes L., Teixera deSousa Jr. P., Schmeda-Hirschmann G., J. Ethnopharmacol., 72, 173-178 (2000).

11) Kahkonen M. P., Hopia A. I., Vuorela H. J., Rauha J. P., Pihlaja K., Kujala T. S., Heinonen M., J. Agric. Food Chem., 47, 3954-3962 (1999) .

12) Takenaka M., Yan X., Ono H., Yoshida M., Nagata T., Nakanishi T., J. Agric. Food
Chem., 51, 793-796 (2003).

13) Takenaka M., Ono H., Nagata T., Kameyama M., Yan X., Kokai Tokkyo Koho., JP 200119664 (2001).

14) Okuda T., Hatano T., Agata I., Nishibe S., Kimura K., Yakugaku Zasshi, 106, 894-899 (1986).

15) Clifford M. N., Kellard B., Food Chem., 34, 81-88 (1989).

16) Adeghate E., Parvez S. H., Toxicology, 153, 143-156 (2000).

17) Uchiyama K., Naito Y., Hasegawa G., Nakamura N., Takahashi J., Yoshikawa T., Redox Rep., 7, 290-293 (2002).

18) Lapidot T., Walker M. D., Kanner J., J. Agric. Food Chem., 50, 7220-7225 (2002). 